\title{
Pengaruh Partisipasi Orang Tua Siswa Terhadap Motivasi Anak Sekolah di Madrasah Aliyah Hidayatullah Mataram
}

\author{
Arsyad Abd. Gani', Suriyawati² \\ ${ }^{1}$ Pendidikan Pancasila dan Kewarganegaraan, Universitas Muhammadiyah Mataram, Email: arsyad.gani@gmail.com \\ ${ }^{2}$ Pendidikan Pancasila dan Kewarganegaraan, Universitas Muhammadiyah Mataram, Email: suriyawati34@gmail.com
}

\begin{abstract}
INFO ARTIKEL
Riwayat Artikel:

Diterima: 21 -

Februari-2019

Disetujui: 28-Maret2019
\end{abstract}

\section{Kata Kunci:}

pengaruh

partisipasi

orang tua

motivasi anak

\begin{abstract}
ABSTRAK
Abstrak: Kendala yang dihadapi Madrasyah adalah masih kurangnya tenaga pengajar, inventaris sekolah, kurangnya fasilitas atau ruang belajar yang memadai menyebabkan proses balajar mengajar kurang efektif. Tujuan penelitian yang ingin dicapai dalam penelitian adalah untuk mengetahui pengaruh partisipasi orang tua siswa terhadap motivasi anak sekolah di MA. Hidayatullah Mataram. Metode yang digunakan dalam penelitian ini adalah metode deskriptif dengan menggunakan pendekatan korelasi. Subjek penelitian ini berjumlah 35 orang. Metode pengumpulan data yang digunakan adalah angket. Adapun jenis data yang digunakan adalah data kuantitatif dengan sumber data primer dan skunder. Sedangkan metode analisis data yang digunakan dalam penelitian ini adalah metode analisis kuantitatif dengan rumus korelasi product moment. Hasil penelitian mnunjukkan pengaruh partisipasi orang tua siswa terhadap ketahanan sekolah di MA. Hidayatullah Mataram. Dengan dasar hasil analisis data yang digunakan dengan angka nilai t-hitunga dalah 0,493, sedangkan untuk nilai t-tabel adalah 0.334, sehingga hipotesis alternative ( $\mathrm{Ha}$ ) yang berbunyi. Ada pengaruh partisipasi orang tua siswa terhadap motivasi anak sekolah di MA. Hidayatullah Mataram diterima, Sedangkan diterima Hipotesis Nihil (Ho) yang berbunyi" Tidak ada pengaruh partisipasi orangtua siswa terhadap motivasi anak sekolah di MA. Hidayatullah Mataram ditolak. Jadi ada pengaruh yang sigifikansi terhadap partisipasi orang tua siswa terhadap motivasi anak dalam menlanjutkan pendidikan.
\end{abstract}

\begin{abstract}
The constraints faced by Madrasah are the lack of teaching staff, school inventory, lack of adequate facilities, or learning space, which makes the learning process less effective. The research objective to be achieved in the study was to determine the effect of parents participation in the motivation of school children in the MA. Hidayatullah Mataram. The method used in this research is a descriptive method using a correlation approach. The subjects of this study were 35 people. The data collection method used is a questionnaire. The type of data used is quantitative data with primary and secondary data sources. While the data analysis method used in this study is a quantitative analysis method with product moment correlation formula. The results of the study show the influence of parents' participation in school resilience in the MA. Hidayatullah Mataram. Based on the results of the data analysis used, the number $t$-hit value is 0.493 , while for the $t$-table value is 0.334 , so the alternative hypothesis (Ha) that reads. There is an influence of parents' participation in the motivation of school children in the MA. Hidayatullah Mataram accepted, while accepted the Zero Hypothesis (Ho) which reads, "There is no influence of parental participation on the motivation of school children in the MA. Hidayatullah Mataram was rejected. So there is a significant effect on parents' involvement in children's motivation in continuing education.
\end{abstract}

\section{A. LATAR BELAKANG}

Setiap sekolah memiliki ciri khas sendiri terhadap output lulusannya, misalnya sekolah madrasyah output lulusan lebih mengedepankan aspek agama daripada ilmu pengetaha umum sedangkan sekolah umum mengedepankan penguasaan ilmu pengetahuan alam, ilmu pengetahuan social daripada agama. Dari perbedaan output lulusan tersebut tentunya memilki tujuan dan harapan yang sama yakni meningkatkan kualitas sumber daya manusia. Upaya tersebut tidak terlepas dari peran pemerintah yang selalu berusaha melakukan berbagai upaya dalam meningkatkan kualitas pendidikan khususnya pendidikan dasar dan menengah.
Berbagai upaya untuk meningkatkan mutu pendidikan tersebut telah dan harus dilakukan, mulai dari berbagai pelatihan untuk meningkatkan kualitas guru, penyempurnaan kurikulum, secara periodik, perbaikan sarana dan prasarana pendidikan sampai peningkatan mutu manajemen sekolah, serta upaya peningkatan kualitas pendidikan ditempuh dalam rangka mengantisipasi berbagai perubahan dan tuntutan kebutuhan masa depan yang akan dihadapi siswa sebagai warga bangsa agar mereka mampu berpikir global dan bertindak sesuai dengan karakteristik dan potensi lokal (think globally but act locally), mengingat dunia telah menjadi "kampung global" [1]. 
Berdasarkan kenyataan yang terjadi bahwa sekolah madrasyah memiliki permasalahan yang paling mendasar yaitu masih kurangnya tenaga pengajar, kurangnya fasilitas atau ruang belajar yang memadai menyebabkan proses balajar mengajar kurang efektif, masih terdapat ruang belajar yang kurang layak sehingga menimbulkan ketidak nyamanan dalam proses kegiatan belajar mengajar. Kekurangan tersebut kurangnya partisipasi masyarakat maupun pemerintah dalam memberikan bantuan fasilitas sarana dan prasarana sekolah.

Hasil penelitian tentang motivasi anak terhadap sekolah di madrasyah menunjukkan hasil yang positif, hal itu sesuai dengan penjelasan bahwa 1) motivasi wali santri tersebut didasari oleh dua faktor, yakni faktor intern yang datang dari dalam diri wali santri misalnya cita-cita, harapan, obsesi, agama dan tanggung jawab sebagai orang tua. Sedangkan faktor ekstern ialah faktor yang datang dari luar seperti lingkungan keluarga, masyarakat maupun daya tarik sekolah di madrasyah. 2) motivasi wali santri menyekolahkan putera-puterinya ke madrasyah antara lain karena sekolah tersebut secara khusus mengajarkan norma dan ilmu agama, biayanya murah, dekat dengan rumah, mampu mendukung pelajaran agama anak di sekolah, serta mengajarkan anak menghargai waktu [2]. Namun menurunnya motivasi anak dipengaruhi oleh lingkungan masyarakat, keluarga dan sekolah meskipun peran orang tua cukup baik. Adapun factor penyebabnya adalah (1) faktor ekonomi, (2) faktor perhatian orang tua, (3) fasilitas pembelajaran, (4) minat anak untuk sekolah, (5) budaya dan (6) faktor lokasi sekolah. Faktor perhatian orang tua menjadi faktor yang paling dominan karena memiliki nilai variance explained tertinggi yaitu sebesar 39,952\%, artinya bahwa perhatian orang tua mampu menjelaskan penyebab anak putus sekolah usia pendidikan dasar di Kecamatan Gerokgak. Faktor lokasi sekolah merupakan faktor yang memiliki variance explained terendah yaitu sebesar 17,014\%[3].

Sementara partisipasi orang tua terhadap tempat anak sekolah masih kurang, hal ini sesuai hasil penelitian sebelumnya menjelaskan bahwa partisipasi orang tua dalam meningkatkan kegiatan pembelajaran dalam pendidikan dengan mengandung diskusi teoritis tentang masalah yang teridentifikasi, seperti studi tentang orang tua partisipasi, bentuk partisipasi orang tua serta penelaahan terhadap kegiatan belajar dengan faktor-faktor yang ada dalam pendidikan, pembelajaran merupakan kebutuhan dasar dalam kehidupan manusia. Manusia tanpa belajar, tidak akan bisa hidup sebagai manusia terutama untuk anak-anak dalam hal tarbiyah spiritualyah tarbiyah adabiyah, tarbiyah aqliyah, tarbiyah jismiyah[4]. Selain itu peran guru juga sangat penting dalam meningkatkan motivasi anak, bahwa peran guru dalam membentuk sikap dan kepribadian siswa yaitu membentuk sikap siswa yang mempertahankan hak dan kewajibannya serta mampu melaksanakan hak dan kewajibannya dengan baik[5].

Berbagai fenomena tersebut sangat penting untuk dilakukan untuk mendapatkan solusinya, salah satu cara yang dilakukan adalah dalam artikel ini akan menjelaskan pengaruh partisipasi orang tua siswa terhadap motivasi anak sekolah di MA. Hidayatullah Mataram. Karena partisipasi orang tua dalam pembangunan pada umumnya dimulai dari tahap pembuatan keputusan, penerapan keputusan, penikmatan hasil, dan evaluasi kegiatan. Secara lebih rinci, partisipasi dalam pembangunan berarti mengambil bagian atau peran dalam pembangunan, baik dalam bentuk pernyataan mengikuti kegiatan, memberi masukan berupa pemikiran, tenaga, waktu, keahlian, modal, dana atau materi, serta ikut memanfaatkan dan menikmati hasil-hasilnya[6].

Melibatkan masyarakat dalam berbagai program dan kegiatan di sekolah yang bersifat sosial kemasyarakatan, seperti bakti sosial, perpisahan, peringatan hari besar nasional, keagamaan, dan pentas seni. Pelibatan masyarakat disesuaikan dengan hobi, kemampuan, dan pekerjaan mereka dengan program dan kegiatan yang akan dilakukan sekolah [7]. Untuk menjadikan sekolah sesuai dengan tujuan dan fungsinya, perlu dilakukan penataan di sekolah melalui langkahlangkah:

1. Meningkatkan koordinasi dan konsolidasai sesama warga sekolah untuk dapat men-cegah sedini mungkin adanya kegiatan dan tindakan yang dapat mengganggu proses belajar mengajar.

2. Melaksanakan tata tertib sekolah secara konsisten dan berkelanjutan.

3. Melakukan koordinasi dengan Komite sekolah dan pihak keamanan setempat untuk terselenggaranya ketahanan sekolah.

4. Mengadakan penyuluhan bagi orangtua dan siswa yang bermasalah

5. Mengadakan penyuluhan dan pembinanan kesadaran hukum bagi siswa.

6. Pembinaan dan pengembangan keimanan, ketaqwaan, etika bermoral Pancasila, kepribadian sopan santun dan berdisiplin.

7. Pengembangan logika para siswa, rajin belajar, gairah menulis, gemar membaca/ informasi/ penemuan para ahli.

8. Mengikutsertakan siswa dalam kegiatan ekstrakurikuler dan pengembangan diri.

9. Mengadakan karya wisata dalam rangka pengembangan iptek.

Demikian juga bahwa partisipasi masyarakat dapat diupayakan dengan lebih dahulu memberikan pelayanan terbaik dari pihak madrasah kepada segenap pengguna madrasah. Pelayanan merupakan hal yang sangat penting sebab madrasah adalah lembaga yang melayani konsumen berupa siswa, dan juga masyarakat umum yang dikenal dengan "stakeholder"[8]. Peran serta 
masyarakat melalui komite dan dewan pendidikan memiliki posisi yang amat strategis dalam mengembangkan tanggung jawab masyarakat. Iklim demokratis dalam pengelolaan sekolah dicerminkan dalam peran masyarakat pada hal-hal: (1) membangun sikap kepemilikan sekolah, (2) merumuskan kebijakan sekolah, (3) membangun kesadaran mutu, (4) perhatian terhadap kehidupan akademik, dan (5) membangun tata kerja kelembagaan sekolah[7]. Peran masyarakat maupun komute sekolah dan orang tua sangat penting demi kemajuan sekolah.

Sementara motivasi anak sekolah di madrasah cukup variasi, keberadaan madrasah ini mempunyai keunikan yakni mengintegrasikan madrasah, pesantren dan panti asuhan, sebagaimana tradisi madrasah lainnya, keshalehan individu yang terepresentasikan dengan keseriusan mencari ilmu agama, melaksanakan ritual ibadah (a'maalul yaumiyah), dan lainnya[9]. Siswa akan terdorong untuk belajar manakala mereka memiliki motivasi untuk belajar. 1) Kuatnya kemauan untuk berbuat, 2) Jumlah waktu yang disediakan untuk belajar, 3) Kerelaan meninggalkan kewajiban atau tugas yang lain, 4) Ketekunan dalam mengerjakan tugas[10]. Dengan demikian tujuan yang dijelaskan dalam artikel ini adalah pengaruh partisipasi orang tua siswa terhadap motivasi anak sekolah di MA. Hidayatullah Mataram.

\section{B. METODE PENELITIAN}

\section{Metode Penelitian yang Digunakan}

Metode yang digunakan dalam penelitian ini adalah metode penelitian deskriptif dengan pendekatan korelasional. Penelitian deskriptif adalah "penelitian yang berusaha mendeskripsikan suatu gejala, peristiwa, kejadian yang terjadi pada saat sekarang"[11].

Ahli lain menyatakan bahwa metode deskriptif, yaitu "suatu metode penelitian yang tertuju pada pemecahan masalah yang ada pada waktu sekarang dengan cara mengumpulkan, menyusun, dan menginterpretasikan arti data dan menarik kesimpulan" [12]. Dengan demikian dapat disimpul-kan bahwa, penelitian deskriptif adalah penelitian yang mendeskripsikan suatu gejala, peristiwa, kejadian yang terjadi pada saat sekarang dengan cara mengumpulkan, menyusun, menginterpretasi-kan arti data dan menarik kesimpulan.

Untuk mengetahui apakah terdapat pengaruh partisipasi orang tua siswa tarhadap ketahanan sekolah di MA. Hidayatullah Mataram Tahun Pelajaran, maka dalam penelitian ini digunakan pendekatan korelasional. Pendekatan korelasional merupakan jenis penelitian yang mengkaji dua hal atau lebih [13]. Pendekatan korelasional ini digunakan untuk menentukan arah korelasi kedua variabel yang diteliti, sebagaimana dijelaskan dibawah ini.

Arah korelasi itu digolongkan menjadi tiga bagian, yakni arah korelasi positif, arah korelasi negatif dan arah korelasi nihil. Arah korelasi positif dapat dijelaskan bahwa apabila variabel $\mathrm{X}$ meningkat maka akan diikuti dengan mening-katnya variabel $\mathrm{Y}$ dan sebaliknya. Sedangkan arah korelasi negatif berarti apabila variabel $\mathrm{X}$ menurun maka akan diikuti dengan meningkatnya variabel $\mathrm{Y}$, demikian sebaliknya apabila variabel $\mathrm{Y}$ meningkat, maka akan diikuti dengan menurunnya variabel X. Arah korelasi nihil artinya kedua variabel tidak memiliki hubungan sama sekali [14].

Penelitian ini akan menggambarkan tentang pengaruh partisipasi orang tua siswa terhadap motivasi anak sekolah di MA. Hidayatullah Mataram, maka hal ini sejalan dengan tujuan penelitian dengan metode deskriptif yaitu suatu metode yang menggambarkan keadaan atau peristiwa yang ada pada saat sekarang dengan cara mengumpulkan data, menyusun, menjelaskan, menganalisa, menginterpretsikan dan menarik suatu kesimpulan berdasarkan hasil penelitian.

\section{Populasi dan Sampel Penelitian \\ a. Populasi}

populasi adalah keseluruhan subyek penelitian [15]. Sedangkan ahli lain menjelaskan bahwa "populasi adalah wilayah generalisasi yang terdiri atas: objek/subjek yang mempunyai kualitas dan karakteristik tertentu yang diterapkan oleh peneliti untuk dipelajari dan kemudian ditarik kesimpulannya"[16].

Berdasarkan kedua pendapat tersebut, maka yang dimaksud dengan populasi adalah keseluruhan subyek yang dimaksud untuk diteliti. Populasi dalam penelitian ini adalah siswa MA. Hidayatullah Mataram. Yang menjadi subyek penelitian yaitu kelas X (sepuluh) MA. Hidayatullah Mataram dengan jumlah populasi sebagai berikut:

Tabel 1

Jumlah populasi

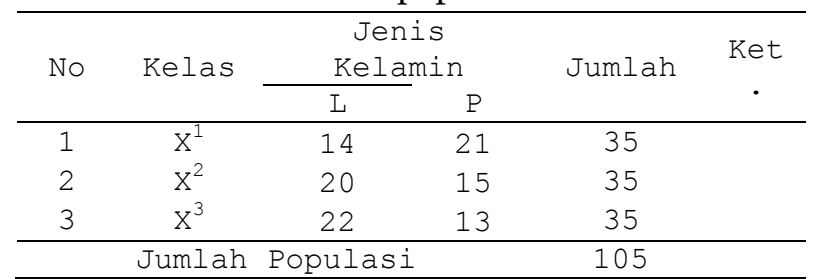

Sumber data: MA. Hidayatullah Mataram

\section{b. Sampel}

Sampel adalah bagian dari jumlah dan karakteristik yang dimiliki oleh populasi [17]. Ahli lain menyatakan bahwa "sampel adalah sebagian atau wakil dari populasi yang diteliti" [15]. Berdasarkan kedua pendapat tersebut, maka yang dimaksud dengan sampel adalah wakil dari populasi. Berdasarkan kedua pendapat diatas,maka yang dimaksud dengan sampel adalah proporsi yang lebih kecil dari populasi yang diselidiki secara langsung.

\section{c. Teknik Sampling}

Teknik sampling adalah merupakan teknik pengambilan sampel [17]. Untuk menentukan sampling yang akan digunakan dalam penelitian ini yaitu dengan menggunakan random sampling. Kerena pengambilan anggota sampel dari populasi dilakukan secara acak. 
Berkaitan dengan teknik pengambilan sampel, Penentuan subjek penelitian yaitu, "untuk sekedar ancer-ancer maka apabila subjeknya kurang dari 100. Lebih baik diambil semua sehingga peneli-tiannya merupakan penelitian populasi dan jika jumlah subjeknya besar dapat diambil $10-15 \%$ atau $20-25 \%$ atau lebih" [17].

Terkait dengan penelitian ini maka sampel yang diambil adalah 35 siswa karena jumlah populasinya lebih dari 100. Yang menjadi sampel penelitian yaitu kelas X (sepuluh) MA. Hidayatullah Mataram dengan jumlah sampel sebagai berikut:

Tabel 2

Jumlah Sampel

\begin{tabular}{cccccc}
\hline \multirow{2}{*}{ No } & \multirow{2}{*}{ Kelas } & $\begin{array}{c}\text { Jenis } \\
\mathrm{L}\end{array}$ & $\begin{array}{c}\text { Kelamin } \\
\mathrm{P}\end{array}$ & Jumlah & $\begin{array}{c}\text { Ket } \\
\text {. }\end{array}$ \\
\hline 1 & $\mathrm{X}^{1}$ & 4 & 8 & 12 & \\
2 & $\mathrm{X}^{2}$ & 5 & 6 & 11 & \\
3 & $\mathrm{X}^{3}$ & 5 & 7 & 12 & \\
\hline \multicolumn{7}{c}{ Jumlah } & & 35 & \\
\hline
\end{tabular}

Sumber data: MA. Hidayatullah Mataram

\section{Jenis dan Sumber Data}

\section{a. Jenis Data}

Sebagaimana diketahi bahwa jenis data itu dapat digolongkan menjadi dua bagian, yakni:

1) Data kuantitatif adalah data yang berbentuk angka atau kualitatif yang dirangkaikan (skoring).

2) Data kualitatif adalah data yang berbentuk kalimat, kata atau gambar (sugiyono , 2007:14)

3) Data yang akan dipergunakan dalam penelitian ini berupa data kuantitatif karena berbentuk angka atau kualitatif yang dirangkaikan (skoring).

\section{b. Sumber Data}

Sumber data dalam penelitian ini adalah subyek dari mana data diperoleh. Menurut [18] sumber data menurut sifatnya digolongkan menjadi 2 yaitu sumber data primer dan sumber data sekunder.

1) Data primer, adalah sumber-sumber yang memberikan data langsung dari tangan pertama.

2) Data sekunder, adalah sumber data yeng mengutip dari sumber data lain.

Berdasarkan pendapat di atas, maka yang menjadi sumber data hasil penyebaran angket.

\section{Identivikasi dan Definisi Operasional Variable}

\section{a. Identifikasi Variabel}

Variable adalah, "gejala gejala yang akan diteliti dalam suatu penelitian" [14]. Variabel adalah "obyek penelitian atau apa yang menjadi titik perhatian suatu penelitian: ada dua jenis fariabel yaitu sebagai berikut:[13]

1) Varibel bebas (independent variabel) yaitu variabel yang secara bebas berpengaruh terhadap varibel lain (variabel terikat).
2) Variabel terikat (independen variabel) yaitu variabel yang dipengaruhi oleh variabel lain (variabel terikat ) sehingga seringkali juga disebut dengan dependent variabel.

Pada penelitian ini yang menjadi variabel bebas adalah partisipasi orang tua siswa, Sedangkan variabel terikatnya adalah motivasi anak sekolah di Madrasah.

\section{b. Difinisi Operasional Variabel}

Untuk menghindari kesalahan dalam penafsiran, maka variabel yang dipergunakan dipa-ndang perlu untuk didefinasikan secara operasio-nal variabel yaitu:

1. Partisipasi orang tua merupakan keikutsertaan orang tua dalam perencanaan, pelaksanaan, pemanfaatan hasil dan evaluasi program pembangunan.

2. Motivasi anak merupakan kuatnya kemauan untuk berbuat, jumlah waktu yang disediakan untuk belajar, kerelaan meninggalkan kewajiban atau tugas yang lain, dan ketekunan dalam mengerjakan tugas.

\section{Teknik Analisi Data}

Metode analisis data yang digunakan dalam penelitian ini adalah metode analisis kuantitatif dengan rumus korelasi product moment sebagai berikut:

$$
\begin{aligned}
& r_{x y}= \\
& \frac{N \sum X Y-\left[\sum X-\mid \sum Y\right]}{\sqrt{\left\{N \sum X^{2}-\left(\sum X\right)^{2}\left\{N \sum Y^{2}-\left(\sum Y\right)^{2}\right\}\right.}}
\end{aligned}
$$

Keterangan:

$r_{x y} \quad=$ Koefisien korelasi produk momen antara variabel $\mathrm{X}$ dan $\mathrm{Y}$

$\mathrm{X}=$ Skor dari partisipasi orang tua siswa

$\mathrm{Y}=$ Skor dari ketahanan sekolah

$\mathrm{N} \quad=$ Jumlah sampel

$\mathrm{Xy} \quad=$ Product $\mathrm{X} \operatorname{dan} \mathrm{Y}$

Adapun langkah-langkah yang dilakukan dalam menganalisa data pada peneltian ini adalah sebagai berikut:

1. Merumuskan Hipotesis Nihil (Ho)

2. Membuat Tabel Kerja

3. Memasukan data Kedalam Rumus

4. Menentukan kuatnya korelasi

5. Menguji Nilai Korelasi Product Moment

6. Menentukan determinasi

7. Menarik Kesimpulan.

Berdasarkan dengan Rumus yang digunakan dalam penelitian pengaruh partisipasi orang tua siswa terhadap ketahanan sekolah agar mengetahui sejauh mana tingkat partisipasinya orang tua tersebut untuk melihat perbandingan antara nilai $\mathrm{X}$ dan nilai $\mathrm{Y}$ [14]. 
84 CIVICUS : Pendidikan-Penelitian-Pengabdian Pendidikan Pancasila dan Kewarganegaraan | Vol. 7, No. 1, Maret 2019, hal $80-88$

\section{HASIL DAN PEMBAHASAN}

\section{Deskripsi Data Partisispasi Orang Tua} Siswa

Tabel 3

Data Hasil Nilai Angket Partisipasi Orang Tua Siswa Di MA. Hidayatullah Mataram

\begin{tabular}{|c|c|c|}
\hline No & Nama & Jumlah \\
\hline 1. & Ayulia sari & 27 \\
\hline 2. & Erni Rihastuti & 26 \\
\hline 3. & Fatmawati & 26 \\
\hline 4. & Hulianti & 27 \\
\hline 5. & Ita deli mardiana & 29 \\
\hline 6. & Johana & 28 \\
\hline 7. & Kartiwi & 27 \\
\hline 8. & Khairunnisa & 29 \\
\hline 9. & Komarul fitri & 28 \\
\hline 10. & Laili Kurnia & 30 \\
\hline 11. & Lisnawati Obi & 32 \\
\hline 12. & Nurhalifah Rasang & 27 \\
\hline 13. & Nuriani & 29 \\
\hline 14. & Nurul hidayati & 31 \\
\hline 15. & Qoriah & 31 \\
\hline 16. & Serli Novita Sari & 31 \\
\hline 17 & Suartini maelani & 31 \\
\hline 18. & Suhani & 30 \\
\hline 19. & Sumiatin zohra & 33 \\
\hline 20. & Wahyuni & 31 \\
\hline 21. & Yuliati & 30 \\
\hline 22. & Mahmudi & 33 \\
\hline 23 . & Yasiman & 33 \\
\hline 24. & Muh.Patoni & $\begin{array}{l}50 \\
33\end{array}$ \\
\hline 25 . & Sayuti & 36 \\
\hline 26. & Jamani & 31 \\
\hline 27. & Ainun & 31 \\
\hline 28. & Mustain & 28 \\
\hline 29. & Zabur & 31 \\
\hline 30. & L.Agus & 29 \\
\hline 31. & Rusdi & 33 \\
\hline 32. & Suryadi & 31 \\
\hline 33 . & Angkasa & 29 \\
\hline 34 . & Saharudin & 31 \\
\hline \multirow[t]{3}{*}{35 . } & Sukardin & 27 \\
\hline & Jumlah & 1049 \\
\hline & Mean/Rata-rata & 29,75 \\
\hline & SD & 2,32 \\
\hline
\end{tabular}

Sumber Data: Diolah

Dari data hasil angket dapat dibuat tabel distribusi frekuensi untuk menentukan nilai rata-rata dan standar deviasi sebagai berikut:

$$
\begin{aligned}
& \mathrm{K}=1+3,3 \log \mathrm{n} \\
& =1+3,3 \log 35 \\
& =1+3,3 \times 1,54 \\
& =1+5,08 \\
& =6,08 \text { (dibulatkan menjadi } 6) \\
& \mathrm{R}=36-26+1=11 \\
& \mathrm{I}=11 / 6=1,83 \text { dibulatkan menjadi } 2
\end{aligned}
$$

Tabel 4

Distribusi Frekuensi Variabel Partisipasi Orang Tua Siswa Di MA. Hidayatullah Mataram

\begin{tabular}{ccccccc}
\hline No & $\begin{array}{c}\text { Kelas } \\
\text { Interval }\end{array}$ & $\begin{array}{c}\text { Freku } \\
\text { ensi } \\
(\mathrm{f})\end{array}$ & $\begin{array}{c}\text { Nengah } \\
(\mathrm{x})\end{array}$ & $\mathrm{x}^{2}$ & f.x & f.x ${ }^{2}$ \\
\hline 1 & $26-27$ & 7 & 26,5 & 702,25 & 185,5 & $\begin{array}{c}7915, \\
75\end{array}$ \\
2 & $28-29$ & 8 & 28,5 & 812,25 & 228 & 6498 \\
& & & & & & 12093 \\
3 & $30-31$ & 13 & 30,5 & 930,25 & 396,5 &, 25 \\
4 & $32-33$ & 6 & 32,5 & 1056,25 & 195 & $\begin{array}{c}6337 \\
5\end{array}$ \\
5 & $34-35$ & 0 & 34,5 & 1190,25 & 0 & 0 \\
5 & $36-37$ & 1 & 36,5 & 1332,25 & 36,5 & $\begin{array}{c}1332, \\
25\end{array}$ \\
\hline & & & & & $\mathbf{1 0 4 1 ,}$ & $\mathbf{3 1 1 7 6}$ \\
6 & jumlah & $\mathbf{3 5}$ & $\mathbf{1 8 9}$ & $\mathbf{6 0 2 3 , 5}$ & $\mathbf{5}$ & $\mathbf{7 5}$ \\
\hline
\end{tabular}

Sumber Data: Diolah

Mean/Rata-Rata

$M=\frac{\sum f x}{N}=\frac{1041,5}{35}=29,75$

Standar Deviasi

$$
S D=\sqrt{\frac{N \cdot \sum f x^{2}-\left(\sum f x\right)^{2}}{N(N-1)}}
$$

$$
S D=\sqrt{\frac{(35)(31176,35)-(1041,5)^{2}}{35(35-1)}}
$$

$S D=\sqrt{\frac{1091172,25-1084722,25}{1190}}$

$S D=\sqrt{\frac{6450}{1190}}$

$$
S D=\sqrt{5,42}=2,32
$$

$$
\begin{aligned}
\longrightarrow & \text { Tinggi }=1=15 \% \\
& \mathrm{M}+1 \mathrm{SD}=29,75 \\
\longrightarrow & \text { Sedang }=8=29 \% \\
& \mathrm{M}-1 \mathrm{SD}=2,32
\end{aligned}
$$$$
\text { Rendah }=21=56 \%
$$ 


\section{Deskripsi Data Motivasi Anak Sekolah di} Madrasyah

Tabel 5

Data asil angket motivasi anak sekolah di MA.Hidayatullah Mataram

\begin{tabular}{|c|c|c|}
\hline No & Nama & Jumlah \\
\hline 1 & Ayulia sari & 31 \\
\hline 2. & Erni Rihastuti & 31 \\
\hline 3. & Fatmawati & 28 \\
\hline 4. & Hulianti & 31 \\
\hline 5. & Ita deli mardiana & 32 \\
\hline 6. & Johana & 31 \\
\hline 7. & Kartiwi & 31 \\
\hline 8 & Khairunnisa & 30 \\
\hline 9. & Komarul fitri & 28 \\
\hline 10 & Laili Kurnia & 31 \\
\hline 11 & Lisnawati Obi & 28 \\
\hline 12 & $\begin{array}{l}\text { Nurhalifah } \\
\text { Rasang }\end{array}$ & 32 \\
\hline 13 & Nuriani & 30 \\
\hline 14. & Nurul hidayati & 30 \\
\hline 15. & Qoriah & 28 \\
\hline 16. & Serli Novita Sari & 30 \\
\hline 17. & Suartini maelani & 30 \\
\hline 18. & Suhani & 29 \\
\hline 19 & Sumiatin zohra & 33 \\
\hline 20 & Wahyuni & 30 \\
\hline 21. & Yuliati & 30 \\
\hline 22. & Mahmudi & 28 \\
\hline 23. & Yasiman & 29 \\
\hline 24. & Muh.Patoni & 31 \\
\hline 25 & Sayuti & 30 \\
\hline 26 & Jamani & 30 \\
\hline 27 & Ainun & 30 \\
\hline 28. & Mustain & 29 \\
\hline 29. & Zabur & 31 \\
\hline 30. & L.Agus & 30 \\
\hline 31. & Rusdi & 29 \\
\hline 32. & Suryadi & 29 \\
\hline 33. & Angkasa & 30 \\
\hline 34. & Saharudin & 29 \\
\hline \multirow[t]{4}{*}{35.} & Sukardin & 33 \\
\hline & Jumlah & 1053 \\
\hline & Mean/rata-rata & 15,02 \\
\hline & SD & 0,7 \\
\hline
\end{tabular}

Sumber Data: Diolah

Dari data hasil angket dapat dibuat tabel distribusi frekuensi untuk menentukan nilai rata-rata dan standar deviasi sebagai berikut:

$$
\begin{aligned}
K= & +3,3 \log \mathrm{n} \\
& =1+3,3 \log 35 \\
= & +3,3 \times 1,54 \\
= & +5,08 \\
= & 6,08 \text { (dibulatkan menjadi } 6 \text { ) }
\end{aligned}
$$

$$
\begin{aligned}
& \mathrm{R}=33-28+1=6 \\
& \mathrm{I}=6 / 6=1
\end{aligned}
$$

Tabel 6

Distribusi Frekuensi Variabel Partisipasi Orang Tua Siswa Di MA. Hidayatullah Mataram

\begin{tabular}{ccccccc}
\hline No & $\begin{array}{c}\text { Kls } \\
\text { Interva } \\
\text { l }\end{array}$ & $\begin{array}{c}\text { Frekuens } \\
\text { i (f) }\end{array}$ & $\begin{array}{c}\text { Nilai } \\
\text { tenga } \\
\text { h (x) }\end{array}$ & $\mathrm{x}^{2}$ & f.x & f.x \\
\hline 1 & 28 & 5 & 14 & 196 & 70 & $\begin{array}{c}980 \\
1261,\end{array}$ \\
2 & 29 & 6 & 14,5 & 210,25 & 87 & 5 \\
3 & 30 & 12 & 15 & 225 & 180 & 2700 \\
4 & 31 & 8 & 15,5 & 240,25 & 124 & 1922 \\
5 & 32 & 2 & 16 & 256 & 32 & 512 \\
6 & 33 & 2 & 16,5 & 272,25 & 33 & 544,5 \\
\hline & & 35 & 91,5 & 1399,75 & 526 & 7920 \\
\hline
\end{tabular}

Sumber Data: Diolah

Mean/Rata-Rata

$$
M=\frac{\sum f x}{N}=\frac{526}{35}=15,02
$$

Standar Deviasi

$$
\begin{aligned}
& S D=\sqrt{\frac{N \cdot \sum f x^{2}-\left(\sum f x\right)^{2}}{N(N-1)}} \\
& S D=\sqrt{\frac{(35)(7920)-(526)^{2}}{35(35-1)}} \\
& S D=\sqrt{\frac{277200-276676}{1190}} \\
& S D=\sqrt{\frac{524}{1190}} \\
& S D=\sqrt{0,44}=0,7
\end{aligned}
$$

\footnotetext{
$\longrightarrow$ Tinggi $=1=15 \%$

$\mathrm{M}+1 \mathrm{SD}=15,02$

$\rightarrow$ Sedang $=8=29 \%$

$\mathrm{M}-1 \mathrm{SD}=0,7$

Rendah $=21=56 \%$
}

\section{Analisis Data}

a. Merumuskan Hipotesis Nihil (Ho)

Untuk keperluan perhitungan analisis statistik, maka hipotesis alternatif ( $\mathrm{Ha}$ ) yang diajukan pada bab II yang berbunyi: "Ada pengaruh partisipasi orang tua siswa terhadap motivasi anak sekolah di MA. Hidayatullah Mataram", perlu diubah terlebih dahulu ke dalam hipotesis nol (Ho) sehingga berbunyi: "Tidak ada pengaruh partisipasi orang tua siswa terhadap motivasi anak sekolah di MA. Hidayatullah Mataram". 
86 CIVICUS : Pendidikan-Penelitian-Pengabdian Pendidikan Pancasila dan Kewarganegaraan | Vol. 7, No. 1, Maret 2019, hal $80-88$

\section{b. Menyusun Tabel Kerja}

Setelah kedua variabel disusun, maka peneliti menggambungkan dan menghitung kedua hasil yang didapat dilapangan supaya mendapat hasil ada tidaknya pengaruh partisipasi orang tua siswa terhadap ketahanan sekolah.

Untuk mengetahui tabel kerja tentang pengaruh partisipasi orang tua siswa terhadap ketahanan sekolah di MA. Hidayatullah Mataram tahun 2011/2012, dapat dilihat dalam tabel berikut: Tabel 7

Mencari Koefisien Korelasi Antara Partisipasi Orangtua Siswa Terhadap Motivasi anak Sekolah di MA. Hidayatullah Mataram.

\begin{tabular}{|c|c|c|c|c|c|c|}
\hline No & Nama orang tua & $X$ & Y & $X^{2}$ & $\mathrm{Y}^{2}$ & $X Y$ \\
\hline 1. & Ayulia sari & 27 & 31 & 729 & 961 & 837 \\
\hline 2. & Erni Rihastuti & 26 & 31 & 679 & 961 & 806 \\
\hline 3. & Fatmawati & 26 & 28 & 679 & 784 & 728 \\
\hline 4. & Hulianti & 27 & 31 & 729 & 961 & 837 \\
\hline 5. & Ita deli mardiana & 29 & 32 & 841 & $\begin{array}{c}102 \\
4\end{array}$ & 928 \\
\hline 6. & Johana & 28 & 31 & 784 & 961 & 868 \\
\hline 7. & Kartiwi & 27 & 31 & 729 & 961 & 837 \\
\hline 8. & Khairunnisa & 29 & 30 & 841 & 900 & 870 \\
\hline 9. & Komarul fitri & 28 & 28 & 784 & 784 & 784 \\
\hline 10. & Laili Kurnia & 30 & 31 & 900 & 961 & 930 \\
\hline 11. & Lisnawati Obi & 32 & 28 & 1024 & 784 & 896 \\
\hline 12. & $\begin{array}{l}\text { Nurhalifah } \\
\text { Rasang }\end{array}$ & 27 & 32 & 729 & $\begin{array}{c}102 \\
4\end{array}$ & 864 \\
\hline 13. & Nuriani & 29 & 30 & 841 & 900 & 870 \\
\hline 14. & Nurul hidayati & 31 & 30 & 961 & 900 & 930 \\
\hline 15. & Qoriah & 31 & 28 & 961 & 784 & 868 \\
\hline 16. & Serli Novita Sari & 31 & 30 & 961 & 900 & 930 \\
\hline 17. & Suartini maelani & 31 & 30 & 961 & 900 & 930 \\
\hline 18. & Suhani & 30 & 29 & 900 & 841 & 870 \\
\hline 19. & Sumiatin zohra & 33 & 33 & 1089 & $\begin{array}{c}108 \\
9\end{array}$ & $\begin{array}{c}108 \\
9\end{array}$ \\
\hline 20. & Wahyuni & 31 & 31 & 961 & 961 & 961 \\
\hline 21. & Yuliati & 30 & 30 & 900 & 961 & 900 \\
\hline 22. & Mahmudi & 33 & 28 & 1089 & 784 & 924 \\
\hline 23. & Yasiman & 33 & 29 & 1089 & 841 & 957 \\
\hline 24. & Muh.Patoni & 33 & 31 & 1089 & 961 & $\begin{array}{c}102 \\
3\end{array}$ \\
\hline 25. & Sayuti & 36 & 30 & 1296 & 900 & $\begin{array}{c}108 \\
0\end{array}$ \\
\hline 26. & Jamani & 31 & 30 & 961 & 900 & 930 \\
\hline 27. & Ainun & 31 & 30 & 961 & 900 & 930 \\
\hline 28. & Mustain & 28 & 29 & 784 & 841 & 812 \\
\hline 29. & Zabur & 31 & 31 & 961 & 961 & 961 \\
\hline 30. & L.Agus & 29 & 30 & 841 & 900 & 870 \\
\hline 31. & Rusdi & 33 & 29 & 1089 & 841 & 957 \\
\hline 32. & Suryadi & 31 & 29 & 961 & 841 & 899 \\
\hline 33. & Angkasa & 29 & 30 & 841 & 900 & 870 \\
\hline 34. & Saharudin & 31 & 29 & 961 & 841 & 899 \\
\hline 35. & Sukardin & 27 & 33 & 729 & 108 & 891 \\
\hline
\end{tabular}

\begin{tabular}{ccccl}
\hline & & \multicolumn{3}{c}{9} \\
\hline 104 & 105 & 31635 & 318 & 316 \\
9 & 3 & & 02 & 36 \\
\hline Sumber data : MA. Hidayatullah Mataram.
\end{tabular}

Sumber data : MA. Hidayatullah Mataram.

\section{c. Memasukan Data Ke dalam Rumus}

Diketahui:

$$
\begin{aligned}
& \mathrm{N} \quad: 35 \\
& \sum \mathrm{Y} \quad: 1053 \\
& \sum \mathrm{X} \quad \text { :1049 } \\
& \sum \mathrm{Y}^{2} \quad: 31802 \\
& \sum \mathrm{X}^{2} \quad: 31635 \\
& \sum \mathrm{XY} \quad: 31636 \\
& r_{x y} \\
& \frac{N \sum X Y-\left[\sum X \mid \sum Y\right]}{\sqrt{\left.\left\{N \sum X^{2}-\left(\sum X\right)^{2}\right\} N \sum Y^{2}-\left(\sum Y\right)^{2}\right\}}} \\
& r_{x y}=\frac{35 \times 31636-1049 \times 1053}{\sqrt{\left\{35 \times 31635-(1049)^{2}\right\}\left\{35 \times 31802-(1053)^{2}\right\}}} \\
& r_{x y}=\frac{1107260-1104597}{\sqrt{\{1107225-1100401\}\{1113070-1108809\}}} \\
& r_{x y}=\frac{2663}{\sqrt{\{6824\}\{4261\}}} \\
& r_{x y}=\frac{2663}{\sqrt{29077064}} \\
& r_{x y}=0,493
\end{aligned}
$$

\section{d. Menentukan Kuatnya Korelasi}

Untuk menentukan korelasi antara partisipasi orang tua siswa dengan motivasi anak sekolah di madrasah, terlebih dahulu penulis menyajikan tabel pedoman untuk memberikan interpretasi koefisien korelasi yaitu sebagai berikut:

Tabel 8

Pedoman Memberikan Interpretasi Koefisien Korelasi $r$

\begin{tabular}{cl}
\hline Interpretasi & \multicolumn{1}{c}{ Tingkat Hubungan } \\
\hline $0.80-1.000$ & Sangat Kuat \\
$0.60-0.799$ & Kuat \\
$0.40-0.599$ & Cukup Kuat \\
$0.20-0.399$ & Rendah \\
$0.00-0.99$ & Sangat Rendah \\
\hline
\end{tabular}
.

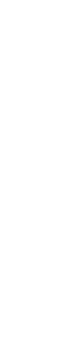$$
\text { . }
$$

\section{.}


Berdasarkan tabel 11 tersebut, maka koefisien korelasi yang di temukan sebesar 0,493 termasuk dalam kategori cukup kuat. Jadi terdapat korelasi yang kuat antara partisipasi orang tua siswa dengan motivasi anak sekolah di MA. Hidayatullah Mataram.

e. Menguji Nilai $r_{x y}$

Langkah selanjutnya adalah menguji nilai rxy yang diperoleh, apakah signifikan atau tidak, berdasarkan hasil dari perhitungan analisis ternyata nilai rxy yang diperoleh dalam penelitian ini adalah sebesar 0,493, nilai itu setelah dikonsultasikan dengan nilai (r) dalam tabel product moment dengan taraf signifikan 5\%/0 dengan jumlah sampel 35 orang, besarnya adalah o,334 maka kenyataan ini menunjukan bahwa nilai rxy yang diperoleh di lapangan lebih besar dari ( $\mathrm{t}$ ) tabel yaitu. o,493>0.334. Dengan demikian hasil penelitian ini dinyatakan signifikan, jadi hipotesis alternatif $(\mathrm{Ha})$ yang berbunyi "Ada pengaruh partisipasi orang tua siswa terhadap motivasi anak sekolah di MA. Hidayatullah Mataram" diterima. Sedangkan Hipotesis nihil (Ho) yang berbunyi "Tidak ada pengaruh partisipasi orang tua siswa terhadap motivasi anak sekolah di MA. Hidayatitullah Mataram" "ditolak".

\section{f. Menentukan Determinasi}

Dari hasil perhitungan pada tabel kerja di atas juga dapat di lihat bahwa besarnya koefisien korelasi antara partisipasi orang tua siswa dan ketahanan sekolah sebesar 0,493. Dari hasil koefisien korelasi tersebut menunjukkan bahwa pengaruh antara kedua variabel cukup kuat. Hal tersebut dapat dilihat dari hasil t-hitung lebih besar daripada nilai t-tabel 0,493 >0,334.

\section{TEMUAN DAN DISKUSI}

Dari hasil pengujian hipotesis (analisis data) dengan menggunakan rumus korelasi product moment ternyata hipotesis alternatif $\mathrm{(Ha)}$ yang diajukan diterima dan hipotesis nihil (Ho) ditolak. Hal ini menunjukkan bahwa "Ada pengaruh partisipasi orang tua sisiwa terhadap motivasi anak sekolah di MA. Hidayatullah Mataram. Dukungan, motivasi, perhatian serta keikutsertaan komite selaku orang tua dalam menjaga mengawasi siswa sehingga tujuan yang diharapkan dalam pendidikan dapat tercapai. Karena pendidikan merupakan tanggung jawab keluarga, masyrakat dan pemerintah.

Pemahaman dasar dan tentunya sangat mendasar dari orang tua/masyarakat (awam/pada umumnya), bahwa sekolah selain membekali kompetensi akademik (pintar), adalah mendidik, membelajarkan anak-anak bangsa ini untuk memiliki norma dan tata nilai sesuai dengan tata laku lingkungannya, budaya bangsa dan agamanya. Oleh karena itu sekolah berkewajiban untuk mengembangkan bentuk perwujudan perilaku (manifested behaviour) yang sesuai dengan norma dan tata nilai, selain yang hanya dapat dipersepsikan (perceived behaviour). Artinya sekolah sebagai lembaga yang memiliki komunitas dan berwujud sebagai masyarakat berbentuk kecil (small community) dipandang penting untuk mengembangkan tata krama dan/atau tata laku dalam kehidupan sekolah dan dilakukan secara nyata dalam kehidupan sehari-hari di sekolah; sehingga dapat berdampak terhadap kehidupan anak-anak di dalam keluarga (rumah), masyarakat, dan kehidupan berbangsa dan bernegara. Departemen Pendidikan Nasional (2001).

\section{E. SIMPULAN DAN SARAN}

Hasil analisis data yang diperoleh menunjukkan an gka 0,493, jika dikonsultasikan dengan nilai t-tabel = o,334, maka nilai t-hitung lebih besar daripada nilai ttabel $0,493>0,334$. Sehingga hipotesis alternatif (Ha) yang berbunyi "Ada pengaruh partisipasi orang tua siswa terhadap motivasi anak sekolah di MA. Hidayatullah Mataram" diterima. Sedangkan hipotesis nihil (Ho) yang berbunyi "tidak ada pengaruh partisipasi orang tua siswa terhadap motivasi anak sekolah di MA. Hidayatullah Mataram" ditolak.

Dukungan dan partiaipasi orang tua siswa sangatlah berpengaruh tarhadap motivasi anak sekolah di MA. Hidayataullah Mataram terbukti dengan motivasi, perhatian serta keikutsertaan komite selaku orang tua dalam menjaga, mengawasi siswa sekolah MA. Hidayatullah Mataram. Dengan adnya perhatian sikap dan dukungan orang tua, guru terhadap siswa dalam belajar, maka tujuan yang di harapkan dalam pendidikan dapat tercapai, karena pendidikan merupakan tanggung jawab keluarga, masyarakat dan pemerintah.

Berdasarkan kesimpulan di atas, maka dapat disarakan sebagai berikut:

1. Kepada kepala sekolah hendaknya selalu berusaha untuk meningkatkan kualitas dan kwantitas pendidikan terhadap ketahanan sekolah dan memberikan kesempatan kepada orang tua siswa untuk berpartisipasi.

2. Kepada Guru, sebagai tenaga pengajar seorang guru hendaknya memperhatikan pendidikan siswa-siswinya, karena sudah menjadi tanggung jawab seorang tenaga pengajar.

3. Kepada Siswa, hendaknya dapat mematuhi peraturan yang berlaku di sekolah dan arahanarahan yang diberikan guru, siswa hendaknya selalu mengikuti perkembangan ilmu pengetahuan dan teknologi yang semakin hari semakin pesat.

4. Kepada orangtua siswa, pendidikan partisipasi orang tua sangat penting atau di perlukan, maka dari itu agar orang tua dapat menyadari akan pentingnya berperan dalam meningkatkan mutu pendidikan terhadap ketahanan sekolah.

5. Kepada masyarakat dan pemerintah, pendidikan merupakan tanggung jawab masyarakat dan pemerintah dengan demikian agar masyarakat dan pemerintah lebih memperhatikan 
pendidikan untuk membangun ketahanan sekolah.

\section{UCAPAN TERIMA KASIH}

Penulis mengucapkan terima kasih kepada semua pihak yang senantiasa memberikan saran dan masukan kepada penulis sehingga artikel ilimiah ini selesai dengan baik.

\section{DAFTAR RUJUKAN}

[1] M. Muslich, "Seri Standar Nasional KTSP Pembelajaran Berbasis Kompetensi dan Kontekstual: Panduan Bagi Guru, Kepala Sekolah, dan Pengawas Sekolah.” Jakarta, 2007.

[2] A. Fachroni, "Motivasi Wali Santri Menyekolahkan Putera-Puterinya Ke Madrasah Diniyah Awaliyah (MDA) Syarif Makamhaji," Universitas Muhammadiyah Surakarta, 2009.

[3] N. A. K. Dewi, A. Zukhri, I. K. Dunia, and M. Erg, "Analisis faktor-faktor penyebab anak putus sekolah usia pendidikan dasar di Kecamatan Gerokgak tahun 2012/2013," J. Pendidik. Ekon. Undiksha, vol. 4, no. 1, 2014.

[4] M. Roesli, A. Syafi'i, and A. Amalia, "Kajian Islam tentang Partisipasi Orang Tua dalam Pendidikan Anak," J. Darussalam J. Pendidikan, Komun. Dan Pemikir. Huk. Islam, vol. 9, no. 2, pp. 332345, 2018.

[5] D. Mutmainah and K. Kamaluddin, "Peran Guru Pendidikan Pancasila Dan Kewarganegaraan Dalam Membentuk Sikap Dan Kepribadian Siswa," Civ. Pendidikan-Penelitian-Pengabdian Pendidik. Pancasila dan Kewarganegaraan, vol. 6, no. 2, pp. 44-53, 2018.

[6] A. Fauzi and D. Sadono, "Persepsi dan Partisipasi Masyarakat Sasaran dalam Program Pengembangan Usaha Kelompok Kecil (Kasus Program Pengembangan Masyarakat PT Aneka Tambang, UPBE Pongkor di Desa Bantar Karet dan Desa Kalongliud, Kecamatan Nanggung Kabupaten Bogor, Jawa Barat)," J. Penyul., vol. 2, no. 3, 2006.

[7] S. R. Mas, "Partisipasi Masyarakat dan Orang Tua dalam Penyelengaraan Pendidikan," elhikmah, vol. 2, no. 1, 2013.

[8] K. A. Rahman, "Peningkatan mutu madrasah melalui penguatan partisipasi masyarakat," $J$. Pendidik. Islam, vol. 1, no. 2, pp. 227-246, 2012.

[9] I. S. Wekke, "Pesantren, Madrasah, Sekolah, Dan Panti Asuhan: Potret Lembaga Pendidikan Islam Minoritas Muslim," At-Tajdid J. Ilmu Tarb., vol. 6, no. 1, pp. 128-144, 2018.

[10] S. Suprihatin, "Upaya guru dalam meningkatkan motivasi belajar siswa," J. Pendidik. Ekon. UM Metro, vol. 3, no. 1, pp. 73-82, 2015.

[11] A. Sudijono, "Pengantar Evaluasi." Pendidikan,(Jakarta: Raja Grafindo Persada, 2001), 2001.

[12] W. Surakhmad, "Penelitian Pendidikan," Jakarta: Rineka Cipta, 2001.

[13] A. Suharsimi, "Prosedur penelitian suatu pendekatan praktik," Jakarta: Rineka Cipta,
2006.

[14] S. Hadi, "Metodologi Penelitian Research jilid II." Yogyakarta: Andi Offset, 2002.

[15] A. Suharsimi, "Prosedur Suatu Pendekatan Praktek," Jakarta PT. Rineka Cipta, 2006.

[16] Sugiyono, "Metode Penelitian kuantitatif kualitatif dan R dan D," Alf. Bandung, 2010.

[17] Sugiyono, Metode Penelitian Pendidikan:(Pendekatan Kuantitatif, Kualitatif dan $R \& D$ ). Alfabeta, 2014.

[18] L. J. Moleong, "Metodologi Penelitian Kualitatif,(Bandung: Remaja Rosdakarya, 2010), cet," Ke-13, $h$, vol. 111. 